\title{
Demographic Gaps in Some Latin American Countries (1985-2020)
}

\author{
Giuseppina Sacco, \\ Pietro Sacco, \\ Department of Economics and Finance, \\ University of Bari, Italy
}

\begin{abstract}
Latin America, in general, is a great geographic, social, political, economic and cultural mosaic and, especially in the demographic field, is far from being a homogeneous aggregate. There have always been, and there are still today, differences between the various countries belonging to this geographical area, both in the ways in which the demographic phenomena have evolved and, mainly, in the times the different steps took for the evolutionary process regarding each of them. This paper will try to monitor the demographic evolution of the countries examined ${ }^{1}$ in the period between the five-year periods 1985-1990 and 2015-2020. In addition, it will identify the possible existence of groupings of countries, similar within them and heterogeneous among them, through the cluster analysis technique, thus highlighting some explanatory indicators that have allowed the above mentioned evolution. The results obtained have led to think that it is necessary to study the economic, social, cultural and institutional aspects of every population, thus being able to cope with differential studies on the mortality and fertility of any population in order to interpret demographic phenomena.
\end{abstract}

Keywords: Transition, Mortality, Fertility

\section{Introduction}

It is well known that the evolution of demographic phenomena is closely linked to the relative environment where it manifests itself.

In this respect, the Latin American continent is so diverse that it does not allow a general study: its geographical, social, political, economic and

${ }^{1}$ The examined countries are: Argentina, Bolivia, Brazil, Chile, Colombia, Ecuador, Paraguay, Peru, Uruguay, Venezuela (in South America); Costa Rica, El Salvador, Guatemala, Honduras, Mexico, Nicaragua, Panama (in Central America); Cuba, Dominican Republic, Haiti (Caribbean countries). 
cultural diversities sometimes lead to the superficial conception that describes it as something unitary in its reality.

Currently, the Latin American area is crossed by a tangle of economic crises, together with social and political tensions. In the economic and social field, for example, there are frightening imbalances: Latin America is the region in the world with the highest degree of social inequality. Suffice it to say that $1 \%$ of the Latin American population owns more than $40 \%$ of the wealth of the entire region.

The region's most influential recent governments have not yet brought new growth, stability and transparency due to their neoliberal policies aimed at weakening social welfare and promoting welfare policies based on the distribution of short-term economic aid rather than on building a sustainable socio-economic structure.

However, it is mainly in the demographic field that the Latin American area does not present itself as a homogeneous aggregate: there are differences in the various countries and in the different areas of the same country. Even the large Latin American cities do not constitute a homogeneous reality; they have two aspects in sharp contrast to each other: on the edge of a city, consisting of skyscrapers, parks and residential neighborhoods, there are very poor neighborhoods without roads, electricity, drinking water, sewers, toilets, etc..

\section{Methodology and data}

The method used to measure the distances between cases (countries) is that of the quadratic Euclidean distance. For the formation of the clusters the criterion of hierarchical type with agglomerative grouping has been adopted, with Ward's algorithm (1963), and for the related methodological deepenings you can see, for example , Delvecchio (2010), Lis and Sambin (1977).

The used and processed data come from an estimate made by the United Nations, Department of Economic and Social Affairs, Population Division, World, Population Prospects (2019).

\section{The population variation}

Like all the quantities concerning the development processes, also the population changes and varies over time.

In this regard, it has been considered more interesting to study the variation, trying to visualize the reasons that determine it, compared to the number of the population itself.

To study the variation of our populations in question in the period between 1985 and 2020, the population variation index numbers has been calculated through the total populations (Table 1). From the reported data it 
can be noticed that in the studied timeframe the population variation pattern has not always been the same in every country. Therefore, in order to make a comparison between two or more numerically different populations, it is necessary to calculate a rate: in this case, the average annual rate of the population variation. This provides the speed at which the population varies over time.

The average annual rate of continuous variation has been used because it assumes that the population variation is continuously updated, moment by moment. We know that

$$
P_{t}=P_{0} e^{r t}
$$

where $P_{t}$ is population at time $t, \quad P_{0}$ is population at time $0, e=2,71828 \ldots$ is the basis of the Neperian logarithms, $r$ is the average annual rate of population variation and $t$ is the time variable. After simple steps the average annual rate of population variation is obtained, namely:

$$
r=\frac{1}{t} \cdot \ln \left(\frac{P_{t}}{P_{0}}\right) .
$$

In Table 1 there are the data of the total population concerning the countries under observation and referring to 1985 and 2020, the population variation index numbers (placed in decreasing order), $1985=100$ and the average annual rates of population variation.

The growth takes place with very different speeds in the various countries of Latin America. It can be inferred that during the period under consideration the populations of two Central American countries have increased more than the other ones and in particular the population of Honduras with a percentage increase of $131.4 \%$ and the population of Guatemala with a positive variation of $117.4 \%$. At the same time, they also record fairly high average annual population rates. In fact, the Honduran population has an average annual rate of $28.8 \%$ (a population increase of about 29 units on average per year for every 1,000 inhabitants) while the Guatemalan population's one is $26.5 \%$.

In the same period, the smallest increase was recorded in the Uruguayan and Cuban population with a percentage of $15.3 \%$ and only $12 \%$ respectively. Actually, the level of their average annual rate is among the lowest of all the other countries, $4.8 \%$ in the Uruguayan population and $3.8 \%$ o in the Cuban one. 
Table 1: Total population (in thousands), index numbers and average annual rates of variation

\begin{tabular}{l|r|r|c|r|l|r|r|r|r}
\hline Countries & 1985 & 2020 & $\begin{array}{c}\text { Index } \\
\text { numbers }\end{array}$ & $1.000 r$ & Countries & 1985 & 2020 & $\begin{array}{c}\text { Index } \\
\text { numbers }\end{array}$ & $1.000 r$ \\
\hline Honduras & 4,281 & 9,905 & 231.4 & 28.8 & Mexico & 75,983 & 128,933 & 169.7 & 17.8 \\
Guatemala & 8,240 & 17,916 & 217.4 & 26.5 & Dominican Rep. & 6,464 & 10,848 & 167.8 & 17.5 \\
Ecuador & 9,066 & 17,643 & 194.6 & 22.6 & Peru & 19,773 & 32,972 & 166.8 & 17.2 \\
Panama & 2,219 & 4,315 & 194.5 & 22.6 & Venezuela & 17,320 & 28,436 & 164.2 & 16.7 \\
Paraguay & 3,676 & 7,133 & 194.0 & 22.5 & Brazil & 135,274 & 212,559 & 157.1 & 15.2 \\
Bolivia & 6,179 & 11,673 & 188.9 & 21.6 & Chile & 12,257 & 19,116 & 156.0 & 14.9 \\
Costa Rica & 2,737 & 5,094 & 186.1 & 21.0 & Argentina & 30,216 & 45,196 & 149.6 & 13.5 \\
Haiti & 6,337 & 11,403 & 179.9 & 19.9 & El Salvador & 4,937 & 6,486 & 131.4 & 9.1 \\
Nicaragua & 3,734 & 6,625 & 177.4 & 19.4 & Uruguay & 3,012 & 3,474 & 115.3 & 4.8 \\
Colombia & 29,951 & 50,883 & 169.9 & 17.9 & Cuba & 10,098 & 11,327 & 112.2 & 3.8 \\
\hline
\end{tabular}

Source: Personal data processing based on United Nations, Department of Economic and

Social Affairs, Population Division, World Population Prospects (2019)

It should be noted, however, that the average annual rate of variation does not provide any information on the demographic dynamics in a given territory because it does not highlight the effects of the natural and migratory components. Therefore, that rate has been broken down into: natural variation rate and migratory variation rate.

The average annual rate of population variation can be considered as the result of the sum of the natural variation rate $\left(v_{n}\right)$ and the migratory variation rate $\left(v_{m}\right)$, i.e.:

$$
r=v_{n}+v_{m}
$$

where the natural variation rate $\left(v_{n}\right)$ is the difference between the birth rate $(n)$ and the mortality rate $(m)$, i.e.:

$$
v_{n}=n-m .
$$

Having at our disposal the total population in 1985 and in 2020 (Tab.1) and the amount of births $(N)$ and deaths $(D)$ (Table 2) occurred during the period considered, the birth and mortality rates can be easily obtained, i.e.:

$$
n=\frac{N / t}{P_{0} \cdot e^{r \cdot \frac{t}{2}}} \quad \text { while } \quad m=\frac{D / t}{P_{0} \cdot e^{r \cdot \frac{t}{2}}}
$$

where $P_{0} \cdot e^{r \cdot \frac{t}{2}}$ represents the population in the middle of the period. 
The calculation of the migratory variation rate can be obtained $\left(v_{m}\right)$ from the difference $^{2}$ between the average annual variation rate $(r)$, and the natural variation rate $\left(v_{n}\right)$, that is:

$$
v_{m}=r-v_{n} .
$$

Table 2: Births and deaths (in thousands), 1985-2020

\begin{tabular}{l|l|l|l|l|l}
\hline Countries & Births & Deaths & Countries & Births & Deaths \\
\hline Argentina & 25,628 & 10,387 & Guatemala & 13,925 & 2,688 \\
Bolivia & 8,718 & 2,792 & Haiti & 9,415 & 3,326 \\
Brazil & 116,933 & 39,769 & Honduras & 7,242 & 1,271 \\
Chile & 9,125 & 3,092 & Mexico & 81,674 & 19,084 \\
Colombia & 29,085 & 7687 & Nicaragua & 4,914 & 1,038 \\
Costa Rica & 2,682 & 613 & Panama & 2,522 & 552 \\
Cuba & 5,005 & 2,916 & Paraguay & 4,962 & 1,078 \\
Dominican Rep. & 7,322 & 1,901 & Peru & 21,757 & 5,425 \\
Ecuador & 11,192 & 2,488 & Uruguay & 1,829 & 1,092 \\
El Salvador & 4,921 & 1,481 & Venezuela & 19,882 & 4,839
\end{tabular}

Source: Personal data processing based on United Nations, Department of Economic and Social Affairs, Population Division, World Population Prospects (2019)

In Table 3 there is the breakdown of the total population average annual variation rates, calculated over the period 1985 to 2020 for all the countries under observation, into natural variation rates and migratory variation rates.

The results show that natural variation rates are positive in all countries with very high levels, especially in the two countries where the average annual variation rate is higher: Honduras (30.6\%) and Guatemala (30.8\%o). Therefore, low levels for Uruguay (7.6\% ) and Cuba (6.5\%o ) can be observed.

As for the migratory variation rates, El Salvador has a strong emigration pressure with a negative rate of $-11.1 \%$ which is the highest among the countries observed. On the other hand, in some countries there is an immigrant pressure: Costa Rica (2.6\%), Chile (1.8\%o ) and Panama (1.4\%o ). In the Brazilian population, however, the migratory variation is zero.

${ }^{2}$ or calculate the net migration as a residue from the population movement equation:

$$
S M=P_{t}-P_{0}-N+D
$$

and then construct the migratory variation rate, namely: $v_{m}=\frac{S M / t}{P_{0} \cdot e^{r \cdot \frac{t}{2}}}$ 
Table 3: Natural, migratory and total variation rates

\begin{tabular}{|c|c|c|c|c|c|c|c|}
\hline Countries & $v_{n}$ & $v_{m}$ & $1.000 r$ & Countries & $v_{n}$ & $v_{m}$ & $1.000 \mathrm{r}$ \\
\hline Honduras & 30.6 & -1.8 & 28.8 & Mexico & 21.1 & -3.2 & 17.8 \\
\hline Guatemala & 30.8 & -4.3 & 26.5 & $\begin{array}{l}\text { Dominican } \\
\text { Rep. }\end{array}$ & 21.6 & -4.1 & 17.5 \\
\hline Ecuador & 22.9 & -0.3 & 22.6 & Peru & 21.3 & -4.1 & 17.2 \\
\hline Panama & 21.2 & 1.4 & 22.6 & Venezuela & 22.6 & -5.9 & 16.7 \\
\hline Paraguay & 25.3 & -2.8 & 22.5 & Brazil & 15.2 & 0.0 & 15.2 \\
\hline Bolivia & 23.3 & -1.7 & 21.6 & Chile & 13.1 & 1.8 & 14.9 \\
\hline Costa Rica & 18.5 & 2.6 & 21.0 & Argentina & 13.7 & -0.2 & 13.5 \\
\hline Haiti & 23.9 & -4.0 & 19.9 & El Salvador & 20.3 & -11.1 & 9.1 \\
\hline Nicaragua & 26.0 & -6.6 & 19.4 & Uruguay & 7.6 & -2.8 & 4.8 \\
\hline Colombia & 18.3 & -0.4 & 17.9 & Cuba & 6.5 & -2.7 & 3.8 \\
\hline
\end{tabular}

Source: Personal data processing based on United Nations, Department of Economic and Social Affairs, Population Division, World Population Prospects (2019)

Therefore, the development and variation of a population over time is determined by the combined action of natural and migratory variations.

At this point, the natural and migratory components should be blocked and a question should be asked: if the average annual variation rates calculated for our countries were destined to remain constant in the future, how long would it take the populations to double their amount?

Starting again from the formula of the continuous increase is required, that is:

$$
P_{t}=P_{0} e^{r t}
$$

which, to answer the question asked, becomes

$$
2=e^{r t}
$$

and after simple steps the doubling time is obtained, namely:

$$
t=\frac{\ln 2}{r} \text {. }
$$

In Table 4 there are the results of the speed that our populations would take if the population average annual variation rate remained constant.

Obviously, the lowest speed is found in the Honduran population that would take only 24 years to double the amount found in 2020 due to a high natural variation $(30.6 \%$ ) mitigated by a negative migration variation $(-1.8 \%)$, while the Cuban population would need 181 years to double its population as they have a low level of natural variation $(6.5 \%)$ which is almost halved by a negative migration variation $(-2.7 \%)$. 
Table 4: Population in 2020, doubling years and doubled population

\begin{tabular}{l|l|l|l|l|l|l|l}
\hline Countries & 2020 & $\begin{array}{l}\text { Doubling } \\
\text { years }\end{array}$ & $\begin{array}{l}\text { Doubled } \\
\text { population }\end{array}$ & Countries & 2020 & $\begin{array}{l}\text { Doubling } \\
\text { years }\end{array}$ & $\begin{array}{l}\text { Doubled } \\
\text { population }\end{array}$ \\
\hline Honduras & 9,905 & 24 & 19,810 & Mexico & 128,933 & 39 & 257,866 \\
Guatemala & 17,916 & 26 & 35,832 & $\begin{array}{l}\text { Dominican } \\
\text { Rep. }\end{array}$ & 10,848 & 40 & 21,696 \\
Ecuador & 17,643 & 31 & 35,286 & Peru & 32,972 & 40 & 65,944 \\
Panama & 4,315 & 31 & 8,630 & Venezuela & 28,436 & 42 & 56,872 \\
Paraguay & 7,133 & 31 & 14,266 & Brazil & 212,559 & 46 & 425,118 \\
Bolivia & 11,673 & 32 & 23,346 & Chile & 19,116 & 46 & 38,232 \\
Costa Rica & 5,094 & 33 & 10,188 & Argentina & 45,196 & 51 & 90,392 \\
Haiti & 11,403 & 35 & 22,806 & El Salvador & 6,486 & 76 & 12,972 \\
Nicaragua & 6,625 & 36 & 13,250 & Uruguay & 3,474 & 146 & 6,948 \\
Colombia & 50,883 & 39 & 101,766 & Cuba & 11,327 & 181 & 22,654 \\
\hline
\end{tabular}

Source: Personal data processing based on United Nations, Department of Economic and Social Affairs, Population Division, World Population Prospects (2019)

Provided that the level of the population variation rate depends on the trend of the three fundamental phenomena of the demography: fertility, mortality and migrations, this study observed the mortality and fertility variations occurred in the countries listed above in the period between 19851990 and 2015-2020, leaving aside migrations.

In demographic literature the spatial variations in mortality and fertility are due to differences in demographic evolution and that this principle is at the basis of the Demographic Transition Theory. Therefore, depending on the indicators that this study will examine and on the calculated population development rates, our countries will be placed in the moment of their demographic transition during the period under observation. It is well known that the classical conception of demographic transition bases its concept on (crude) birth rates and on (crude) mortality rates, but this study will refer to mortality and fertility measures that, in the case of mortality, are independent from the population composition by age, and, in the case of fertility, are independent from the age structure of the female fertile population.

\section{The transition of mortality}

The demographic phenomenon that usually initiates the process of demographic transition is mortality. By virtue of this concept, it is important to understand what it depends on and to explain the variations that lead to its decrease.

The two indicators that directly affect mortality are: infant mortality rate and life expectancy at birth. A decrease in the infant mortality rate implies that more children reach adulthood, while an increase in life expectancy at birth implies that people have a higher survival rate. 
The infant mortality rate, referred in the strict sense to deaths occurring in the first year of life, gives us the frequency of infant deaths in the first year of life coming from live births in a year.

Analyzing the countries separately, it can be noticed that in the fiveyear period 2015-2020 infant mortality rates are between $4.0 \%$, that is 4 deaths in the $1^{\text {st }}$ year of life per 1,000 live birth (the lowest level, found in the Cuban population), and $54.0 \%$, that is 54 deaths in the $1^{\text {st }}$ year of life per 1,000 live births (the highest level, recorded in Haitian population)-(Table 5).

Table 5: Infant mortality rates (\%o ) - 2015-2020

\begin{tabular}{l|l|l|l}
\hline Countries & $\begin{array}{l}\text { Infant } \\
\text { Mortality rates }\end{array}$ & Countries & $\begin{array}{l}\text { Infant } \\
\text { Mortality rates }\end{array}$ \\
\hline Haiti & 54,0 & Mexico & 14,0 \\
Bolivia & 30,0 & Panama & 14,0 \\
Dominican Rep. & 26,0 & Brazil & 13,0 \\
Venezuela & 26,0 & Colombia & 13,0 \\
Guatemala & 21,0 & Peru & 13,0 \\
Paraguay & 19,0 & Argentina & 10,0 \\
Nicaragua & 17,0 & Uruguay & 9,0 \\
El Salvador & 15,0 & Chile & 7,0 \\
Honduras & 15,0 & Costa Rica & 7,0 \\
Ecuador & 14,0 & Cuba & 4,0 \\
\hline Source: Pera
\end{tabular}

Source: Personal data processing based on United Nations, Department of Economic and Social Affairs, Population Division, World Population Prospects (2019)

Life expectancy at birth, on the other hand, is the most widespread and efficient indicator for comparing mortality levels among populations as it is an indicator independent of the population composition by age. Life expectancy at birth indicates the average number of years left to a newborn male or female.

It is obvious that an increase in life expectancy at birth, which is an indicator of good living conditions for the population and in particular health conditions, determines greater population survival but it has a smaller impact than the decrease in infant mortality as this one does not change but could increase, instead, the number of the individuals of reproductive age.

In Table 6 the values of life expectancy at birth for women (values in descending order) and for men respectively refer to the five-year period 20152020 .

From the values of life expectancy at birth, it can be deduced that the level of mortality in the analysed countries has decreased over time. This is due in large part to the decrease of mortality - different in the various countries - in the $1^{\text {st }}$ year of life, because the highest levels of life expectancy at birth were found in the countries where infant mortality was low (Costa Rica, Cuba, Chile, Uruguay). 
If the every single country is analysed at the present time, it can be seen see that in some of them women's life expectancy at birth is over 80 years, while the population of Haiti has very low values for both sexes, thus reflecting the high mortality rate in the $1^{\text {st }}$ year of life.

Table 6: Values of life expectancy at birth - 2015-2020

\begin{tabular}{l|l|l|l|l|l}
\hline Countries & Females & Males & Countries & Females & Males \\
\hline Costa Rica & 82,66 & 77,43 & Mexico & 77,83 & 72,10 \\
Chile & 82,32 & 77,44 & Nicaragua & 77,66 & 70,61 \\
Panama & 81,53 & 75,13 & El Salvador & 77,54 & 68,11 \\
Uruguay & 81,30 & 73,87 & Honduras & 77,28 & 72,68 \\
Cuba & 80,67 & 76,72 & Dominican Rep. & 77,12 & 70,72 \\
Argentina & 79,80 & 73,00 & Guatemala & 76,80 & 71,00 \\
Colombia & 79,78 & 74,23 & Paraguay & 76,20 & 72,11 \\
Ecuador & 79,56 & 73,95 & Venezuela & 76,08 & 68,40 \\
Brazil & 79,27 & 71,90 & Bolivia & 74,05 & 68,28 \\
Peru & 79,18 & 73,71 & Haiti & 65,68 & 61,37 \\
\hline
\end{tabular}

Source: Personal data processing based on United Nations, Department of Economic and Social Affairs, Population Division, World Population Prospects (2019)

\section{3. $\quad$ The transition of fertility}

The variation in fertility is measured by the total fertility rate considered as the average number of children a woman will have throughout the period of her fertile life: it is an indicator that allows comparisons to be made in time and space between fertility levels as it is independent of the structure by age of the female fertile population.

In Table 7 there are the levels of total fertility rates (in descending order) referring to the five-year period 2015-2020.

By analysing the data of every single country, the level of total fertility rates in the current period varies between a minimum of 1.62 in the Cuban female population, which is below the replacement value (2.1), and a maximum in the Haitian female population $(2,96)$.

The reason why fertility decreases or does not decrease in a given country brings us back to other personal considerations related to religion, economic well-being, information for women on methods of contraception, education, urbanization, and so on, which are all outside the aim of this study. 
Table 7: Total fertility rates $-2015-2020$

\begin{tabular}{l|l|l|l}
\hline Countries & $\begin{array}{l}\text { Total } \\
\text { Fertility rate }\end{array}$ & Countries & $\begin{array}{l}\text { Total } \\
\text { Fertility rate }\end{array}$ \\
\hline Haiti & 2,96 & Argentina & 2,27 \\
Guatemala & 2,90 & Peru & 2,27 \\
Bolivia & 2,75 & Mexico & 2,14 \\
Honduras & 2,49 & El Salvador & 2,05 \\
Panama & 2,47 & Uruguay & 1,98 \\
Paraguay & 2,45 & Colombia & 1,82 \\
Ecuador & 2,44 & Costa Rica & 1,76 \\
Nicaragua & 2,42 & Brazil & 1,74 \\
Dominican Rep. & 2,36 & Chile & 1,65 \\
Venezuela & 2,28 & Cuba & 1,62
\end{tabular}

Source: Personal data processing based on United Nations, Department of Economic and Social Affairs, Population Division, World Population Prospects (2019)

\section{Structural changes}

Conventionally, a population can be divided into three groups: young population (0-14 years), adult population (15-64 years) and elderly population (65 years and over). From the dynamic point of view three types of population are obtained:

a) a population of progressive type, when the number of young people ( 0 14 years) is greater than the elderly population's one (65 years and over);

b) a population of a stationary type, when the number of young people ( $0-14$ years) and the elderly population's one (65 years and over) are equivalent and roughly represent $25 \%$ of the total population;

c) population of regressive type, when the number of young people (0-14 years) is lower than the elderly population's one (65 years and over).

For the countries under observation, this study divided their populations into the three classes mentioned above and calculated the percentages on the total of the population in 2020. It immediately emerges that in the Cuban population the extreme classes, that is ( $0-14$ years) and (65 years and over) are in perfect balance (15.9\%), so this population could fall into the stationary type, while all other populations are of progressive type, therefore the amount of young people (0-14 years) is greater than the elderly population's one (65 years and over).

The first signs of population ageing, however, begin to emerge in the populations where the aging index (percentage ratio between the 65 years and over age group and the total amount of the population) exceeds $10 \%$ (Table $8)$.

If the ageing of the population is an unavoidable consequence of the advancement of the demographic transition processes - in the sense that, as a 
rule, the more these processes progress, the higher the proportion of older people is - the countries with an ageing rate of more than $10 \%$ should be ahead of others when the demographic transition process begins to be completed.

Table 8: Breakdown of population age groups in percentages - 2020

\begin{tabular}{l|l|l|l|l|l|l|l|l|l}
\hline Countries & $0-14$ & $15-64$ & $65+$ & Total & Countries & $0-14$ & $15-64$ & $65+$ & Total \\
\hline Argentina & 24.4 & 64.2 & 11.4 & 100.0 & Guatemala & 33.3 & 61.6 & 5.0 & 100.0 \\
Bolivia & 30.2 & 62.3 & 7.5 & 100.0 & Haiti & 32.5 & 62.3 & 5.2 & 100.0 \\
Brazil & 20.7 & 69.7 & 9.6 & 100.0 & Honduras & 30.6 & 64.4 & 5.0 & 100.0 \\
Chile & 19.2 & 68.5 & 12.2 & 100.0 & Mexico & 25.8 & 66.5 & 7.6 & 100.0 \\
Colombia & 22.2 & 68.8 & 9.1 & 100.0 & Nicaragua & 29.5 & 64.8 & 5.7 & 100.0 \\
Costa Rica & 20.8 & 68.9 & 10.3 & 100.0 & Panama & 26.5 & 65.0 & 8.5 & 100.0 \\
Cuba & 15.9 & 68.2 & 15.9 & 100.0 & Paraguay & 28.9 & 64.3 & 6.8 & 100.0 \\
Dominican Rep. & 27.4 & 65.0 & 7.5 & 100.0 & Peru & 24.7 & 66.6 & 8.7 & 100.0 \\
Ecuador & 27.4 & 65.0 & 7.6 & 100.0 & Uruguay & 20.3 & 64.6 & 15.1 & 100.0 \\
El Salvador & 26.6 & 64.8 & 8.6 & 100.0 & Venezuela & 27.3 & 64.8 & 8.0 & 100.0 \\
\hline
\end{tabular}

Source: Personal data processing based on United Nations, Department of Economic and Social Affairs, Population Division, World Population Prospects (2019)

\section{Differences and similarities}

To visualize the existence of possible groups of homogeneous countries within them and heterogeneous among them the cluster analysis technique will be adopted. This will help outline the demographic transition models where the countries examined are currently located.

The study considered all the indicators already built. Some refer to the five-year period 2015-2020 and others to the single year 2020. The variables have been previously standardized to prevent the unit of measurement from affecting the variables.

By applying cluster analysis, the 5-group partition (Table 9) proved to be the most suitable to distinguish the cluster of the countries observed. In the light of the results of this analysis, five transition models have emerged for the countries concerned.

In the first group, which could be defined as a "very advanced transition", there are 2 countries: Cuba and Uruguay.

In the second group, which could be defined as "advanced transition", there are 7 countries: Ecuador, Panama, Costa Rica, Chile, Colombia, Brazil and Argentina.

In the third group, which could be defined as a "limited transition", there are 7 countries: Mexico, Dominican Republic, Peru, Venezuela, Paraguay, Nicaragua and El Salvador.

In the fourth group, which could be defined as "moderate transition", there are 3 countries: Honduras, Guatemala and Bolivia.

In the fifth group, which could be defined as "the initial transition", there is only 1 country: Haiti. 
Table 9: Average values per cluster

\begin{tabular}{l|l|l|l|l|l}
\hline Indicators & Group 1 & Group 2 & Group 3 & Group 4 & Group 5 \\
\hline Variation rate & 4.3 & 18.2 & 17.2 & 25.6 & 19.9 \\
- natural variation & 7.1 & 17.6 & 22.6 & 28.2 & 23.9 \\
- migratory variation & -2.8 & 0.7 & -5.4 & -2.6 & -4.0 \\
Infant mortality & 6.5 & 11.1 & 18.6 & 22.0 & 54.0 \\
Life expectancy at birth (females) & 80.99 & 80.70 & 77.37 & 76.04 & 65.68 \\
Life expectancy at birth (males) & 75.30 & 74.73 & 70.82 & 70.65 & 61.37 \\
Total Fertility Rate (TFR) & 1.80 & 2.02 & 2.28 & 2.71 & 2.96 \\
Ageing index & 15.5 & 9.8 & 7.6 & 5.8 & 5.2 \\
Countries total & 2 & 7 & 7 & 3 & 1 \\
\hline
\end{tabular}

Source: Personal data processing based on United Nations, Department of Economic and Social Affairs, Population Division, World Population Prospects (2019)

It seems superfluous to comment the data concerning the various groups because, passing from a group to another one, the trend of the indicators characterizing the demographic transition confirms the current phase in which the countries are found, that is: 1) the infant mortality is increasing; 2) both male and female life expectancy at birth is decreasing; 3) the total fertility rate is increasing; 4) the ageing index is decreasing.

\section{Concluding remarks}

In this study, the analysis of the demographic gaps existing in some Latin American countries under observation has led to the evolutionary process known as the "theory of demographic transition", which, in the long term, favours the analysis of fertility and mortality,.

Presently, this evolution process is well differentiated in the different areas of our planet: if the advanced development countries have already finished their transitional process and are projected towards the posttransitional phase - the so-called second demographic transition -, other countries, in this case the Latin American ones, are now going through their final phases.

However, in order to better understand this process and to affirm that only the advanced development countries - therefore the richest, the most modern and economically strong - have completed their transitional process, it is necessary to look at the context within which it takes place, bearing in mind economic, social, cultural and institutional aspects.

The most emblematic and paradoxical case is to be found in one of our countries: Cuba.

In general, there is a tendential relationship between a country's state of economy and the "health" of its population: in a country where wealth thrives, survival increases. Even if they have already entered the last step of the transitional process, this "law" is not applicable to the Cuban population: 
they have a GDP per capita equal to the developing countries' one $\left(8,821^{3}\right.$ dollars per year), but their survival indicators, such as infant mortality (4\%o) and life expectancy at birth of females (80.67 years) and males (76.72 years), are equal to the developed countries' ones, and sometimes even better.

So, in this case, the "paradox" of the Cuban health system should be carefully evaluated: if the economic resources are scarce but the results are excellent, what are the strengths of the Cuban health system?

Again, there is a tendential relationship between the state of a country's economy and the reproductive capacity of women: as it happens in the advanced development countries, in a country where wealth thrives the fertility rate decreases. Here is another paradox of the Cuban population: on the one hand, the precarious economic situation leads many young people to emigrate while, on the other hand, it leads to a decreasing trend in the number of children in order to have a smaller family and feel better economically.

In Cuba the level of the total fertility rate (1.62) is equal to or lower than the one we find in an advanced development country. Looking ahead, all projections predict an exceptional demographic ageing in Cuban population in the next ten years. All these signals are already present in the advanced development countries that are economically stronger and have already concluded their transitional process.

Therefore, the contradictions existing between the Cuban population and the populations that have concluded the transitional process reveal that the trend of the decreasing curves of mortality and fertility - which is a clear symptom of the end of this process, cannot be generalized to the other populations but it is necessary to study the economic, social, cultural and institutional aspects of every single population.

The last country this study analysed is Haiti. This country is only at the beginning of the transition and is struggling to abandon the demographic indicators characterizing the backwardness regime: the demographic transition still lags behind the other Caribbean countries ${ }^{4}$. The analysis of the average values per cluster (Table 9) shows that Haiti is indeed one of the poorest countries in the world. Moreover, also the environmental disasters that are taking place (e.g. deforestation, use of pesticides) have brought the population below the poverty line.

\section{References:}

1. Delvecchio F., (2005), Statistica per la ricerca sociale, Cacucci ed.

2. Golini, A. (2003), La popolazione del pianeta, Il Mulino.

\footnotetext{
${ }^{3}$ World Bank 2018

${ }^{4}$ Dossier CDS HAITI, 2017. CARITAS AMBROSIANA
} 
3. Golini, A. (a cura di), (2009), Il futuro della popolazione del mondo, Il Mulino.

4. Livi Bacci, M., Introduzione alla Demografia, ultima edizione, Loescher Ed.

5. Livi Bacci, M. (2002), Storia minima della popolazione del mondo, Il Mulino.

6. Myrskyla, M., Kohler H.P., Billari, F.C., (2009), Advances in development reverse fertility declines, Nature volume 460, pages741743.

7. Sacco, G., Sacco P. (2016). The ageing scenario of the Italian Population (Vol.12, N.35). Publisher ESI, ISSN: 1857 - 7431 (Online), December, (pp. 1 -15).

8. Sanderson, W., Scherbov, S. (2007). A new perspective on population aging. Demographic Research 16, (pp. 27-58).

9. Società italiana di Statistica, (2007), Rapporto sulla popolazione. L'Italia all'inizio del XXI secolo, Il Mulino.

10. United Nations, Department of Economic and Social Affairs. Population Division, Population Estimates and Projections Section, World Population Prospects (2019)

11. United Nations, World Population Prospects. The 2008 Revision, New York, 2009

12. www.un.org/en/development/desa/population/index.asp

13. www.worldbank.org 